\title{
KOMUNIKASI TRANSAKSIONAL - DIALEKTIS DALAM DRAMA ELEKTRA KARYA SOPHOKLES
}

\section{TRANSACTIONAL COMMUNICATION - DIALECTICAL IN ELEKTRA DRAMA BY SOPHOKLES}

\author{
Abdul Muhaiminul Aziz \\ Prodi Ilmu Komunikasi Stikosa - AWS \\ Email : abdulmuhaiminulaziz981@gmail.com
}

\begin{abstract}
This article qualitatively describes the transactional-dialectic communication of the character Elektra in Sophokles's drama Elektra. In communicating, Elektra, who has been unjustly wronged, applied the elements of transactional communication: feedback, talk, response, action and reaction. Dialectically, conversations between Elektra and her partner that are discussed in this article were those involving conflict or opposition. Moreover, there were principles of Marxist dialectics: no static or constant probability, make good use of any chance for a good objective, build contradictive relation for negating past mistakes, and prefer revolution to public peace while sacrificing oneself. Data were collected through purposive sampling. The collected data were analyzed using discourse analysis method for dramatic text. The results of analysis showed that by communicating dialectically Elektra succeeded in reaching her good purpose, she got the real justice when her father's murderers reaped the harvest of their work.
\end{abstract}

Keywords: transactional communication, Marxist dialectics, dramatic literature

\begin{abstract}
ABSTRAK
Artikel ini mendeskripsikan secara kualitatif komunikasi transaksional-dialektis tokoh Elektra dalam drama Elektra karya Sophokles. Dalam berkomunikasi, Elektra yang sudah disalahi secara tidak adil menerapkan unsur-unsur komunikasi transaksional yang berupa timbal balik, pernyataan, tanggapan, aksi dan reaksi. Secara dialektis, percakapan antara Elektra dan lawan bicaranya yang dibahas di dalam artikel ini adalah yang melibatkan konflik atau oposisi. Selain itu, ada prinsipprinsip dialektika Marxisme: tidak ada kemungkinan yang statis atau konstan, memanfaatkan celah sekecil apapun demi tujuan mulia, membangun relasi kontradiktif demi penegasian kesalahan, dan berpihak pada revolusi bukan pada ketentraman khalayak tapi mengorbankan diri sendiri. Data dikumpulkan melalui purposive sampling. Data yang sudah terkumpul dianalisis dengan metode analisis wacana untuk teks yang berupa drama. Hasil analisis menunjukkan bahwa dengan berkomunikasi dialektis Elektra berhasil meraih tujuan mulia, berupa mendapatkan keadilan yang sebenarnya, yakni pembunuh ayahnya memperoleh balasan setimpal. Kata-kata Kunci: komunikasi transaksional, dialektika Marxisme, sastra drama
\end{abstract}

ISSN 2338 - 0861 (cetak); e-ISSN 2621 - 8712 (online)

website : http://spektrum.stikosa-aws.ac.id 


\section{PENDAHULUAN}

Komunikasi, dalam batasan tertentu, adalah salah satu cara yang digunakan manusia untuk mencapai tujuan. Kata-kata atau bahasa apa saja yang dikomunikasikan memungkinkan manusia meraih apa yang diinginkannya. Dalam sebuah model komunikasi klasik, Lasswell (1948) memformulasikan bahwa komunikasi adalah menjawab pertanyaan siapa, berkata apa, kepada siapa, melalui apa, dan apa dampaknya. Walaupun Model Lasswell ini sudah sangat layak disebut kuno, di sekolah-sekolah komunikasi pendapat Lasswell ini masih dijadikan acuan dalam perkuliahan maupun penelitianpenelitian akademis. Ibarat kata, model Lasswell seyogyanya disebut model legendaris dalam studi ilmu komunikasi.

Para pakar komunikasi berpendapat bahwa model Lasswell itu memiliki kelemahan pada tidak adanya konteks dan timbal balik (feedback). Padahal, sudah lazim bahkan dalam percakapan sehari-hari sekalipun, pembicara dan lawan bicara saling merespon dengan timbal balik secara berkelanjutan. Oleh karena itu, pakar komunikasi menciptakan model transaksional. Burgoon dan Ruffner (1978) menyatakan bahwa yang dimaksud transaksional di sini adalah pembicara dan lawan bicara itu memberikan timbal balik, pernyataan, tanggapan, aksi dan reaksi secara terus menerus dalam peristiwa komunikasi.

Di dalam karya sastra, khususnya drama, ada perlakuan istimewa terhadap intensitas terjadinya komunikasi yang berupa percakapan antar tokoh. Tokoh-tokoh dalam drama pada umumnya berkomunikasi secara transaksional dan setiap drama pasti memiliki konteks yang sengaja sudah diciptakan oleh dramawan. Misalnya, dalam drama Elektra karya Sophokles, dramawan Yunani purba, tokoh utama, yakni Elektra, adalah orang yang sudah disalahi secara tidak adil. Seluruh percakapan yang melibatkan Elektra dalam drama ini tidak akan lepas dari perkara keadilan dan ketidakadilan. Ayah Elektra, Agamemnon, dibunuh oleh istrinya sendiri, yakni ibu kandung Elektra, yaitu Klytaimestra dengan bisikan selingkuhan Klytaimestra yang bernama Aigisthos. Sebagai tokoh utama yang dialektis, Elektra memiliki kemampuan berkomunikasi dengan baik. Hal ini bisa dilihat dari percakapan-percakapannya yang melibatkan, paling sedikit, lima komponen dalam model komunikasi yang dibuat Burgoon dan Ruffner. Selain itu, ada hukum-hukum dialektika dalam konten komunikasi yang disampaikan Elektra. Sasongko (2016) meneliti cinta dialektis dalam film Ada Apa dengan Cinta 1 dan 2. Sementara itu, Baxter (2004) meneliti dialektika relasional dalam novel Dickens A Tale of Two Cities. Sasongko menggunakan dialektika Marx sedangkan Baxter mengaplikasikan dialektika Hegel. Mempertimbangkan karakter Elektra yang radikal dan revolusioner seperti Rangga dan Cinta, artikel ini akan mengusung dialektika Marx sebagaimana penelitian Sasongko. Perbedaannya, Sasongko memusatkan perhatian pada tujuan Rangga dan Cinta yang berupa cinta, sedangkan Elektra pada keadilan. Selain itu, penelitian Sasongko sama sekali tidak melibatkan komunikasi transaksional, berbeda dengan penelitian ini. 
Croucher (2015) menjelaskan lebih lanjut mengenai apa yang dimaksud dengan komunikasi transaksional. Komunikasi dianggap sebagai aktivitas tarik ulur antara penyampai dan penerima pesan. Timbal balik sangat penting dalam komunikasi. Tapi dari sudut pandang transaksional, komunikasi lebih jauh dari sekadar menekankan timbal balik. Penyampai dan penerima pesan saling memengaruhi dalam proses komunikasi.

Masing-masing individu yang terlibat dalam komunikasi adalah pengirim pesan dan pada saat yang sama dia adalah penerima pesan. Pengirim dan penerima pesan memproses pesan untuk dikirim (encoding) dan memproses pesan yang diterima (decoding). Kanal komunikasi mereka adalah verbal, non-verbal atau melalui gawai dalam jaringan internet. Apapun kanal komunikasi yang mereka gunakan, mereka mengirim dan menerima pesan. Tetapi, kita sering menyalahartikan pesan dan kita bisa salah memaknai pesan yang kita terima. Salah satu yang menyebabkan ini adalah derau (noise). Derau adalah apa saja yang mengganggu pemahaman kita terhadap pesan komunikasi. Derau fisiologis bisa berupa rasa lapar, lelah, sakit kepala, depresi, pengobatan dan perkara lain yang memengaruhi apa yang kita rasakan. Derau fisik adalah hal-hal yang mengganggu komunikasi, seperti bunyi lantang dan cahaya terang. Derau psikologis adalah keadaan di dalam diri kita yang membatasi kemampuan kita untuk memaknai pesan secara tepat, misalnya kebencian tak berdasar, mempertahankan diri, bosan, jatuh cinta, dan lain-lain. Derau semantik ialah ketika kata-kata tak bisa dipahami. Pendekatan transaksional memperhatikan kompleksitas komunikasi (Croucher, 2015).

$$
\text { Penelitian }
$$

mengenai

karakterisasi tokoh Elektra untuk mengungkap tema drama Elektra pernah dilakukan oleh Aziz (2005). Analisis karakterisasi dalam penelitian Aziz terfokus pada percakapan-percapakan yang mengandung konflik. Ini sejalan dengan prinsip dasar dialektika, yaitu adanya oposisi atau kontradiksi. Selain itu, dalam dialektika, tidak ada yang ceteris paribus, artinya "setiap kemungkinan tidak diandaikan statis atau konstan" (Sasongko, 2016). Ini mengandung arti bahwa manusia harus memperjuangkan apa yang dicita-citakannya.

$$
\text { Dialektika }
$$

Marxisme mengajarkan kepada manusia agar memanfaatkan celah sekecil apa pun demi tercapainya tujuan yang sudah ditetapkan. Tujuan ini harus diperjuangkan walaupun mesti dilalui dengan kekecewaan, kesedihan, dan penderitaan. Selain itu di dalam dialektika ada usaha untuk membangun relasi yang kontradiktif demi terciptanya kemungkinan untuk menegasikan semua kesalahan terdahulu. Manusia tidak akan bisa bebas sama sekali dari kesalahan. Tetapi, manusia diberi kesempatan untuk berdialektika guna memperbaiki diri agar tidak selamanya terkungkung dalam perasaan bersalah dan tak berdaya di hadapan keadaan yang tidak diinginkan. Dialektika memihak pada revolusi. Manusia yang revolusioner tidak akan menjadi fungsionalis yang memilih menjaga ketentraman khalayak walaupun harus mengorbankan diri sendiri (Sasongko, 2016).

\section{METODOLOGI}

website : http://spektrum.stikosa-aws.ac.id 
Dalam penelitian ini, data dikumpulkan melalui purposive sampling, yaitu pengambilan data melalui serangkaian pilihan strategis tentang dengan siapa, di mana, dan bagaimana seseorang melakukan penelitian (Palys, 2008). Dalam konteks studi ini, purposive sampling yang diterapkan adalah criterion sampling dan theory-guided sampling. Data yang berupa kata-kata dari drama Elektra diambil berdasarkan kriteria yang sudah ditetapkan dan sesuai dengan teori komunikasi transaksional dan teori dialektika Marxisme yang sudah dikaji sebelumnya.

Data yang sudah terkumpul akan dianalisis dengan metode analisis wacana untuk teks yang berupa drama. Hess-Luttich (1985) menyebutkan tiga jenis dialog oleh Murakovsky, yaitu: antagonistic dialogues (sering menggunakan kata ganti personal pihak-pihak yang berlawanan dan bentuk-bentuk imperatif, vokatif, interogatif, adversatif, dan lainnya), empractical dialogues (ditambahkan dalam situasi dan aksi dengan menggunakan bentuk-bentuk deiksis khusus, kata ganti demonstratif, bentuk waktu sekarang, dan lainnya), dan conversational dialogues (topiknya bebas, situasinya independen, ujarannya bersifat umum untuk interaksi sosial biasa). Lebih lanjut Hess-Luttich menyebutkan jenis-jenis kelas wacana berdasarkan kriteria yang bisa disesuaikan dengan kriteria komunikasi transaksional dialektis, antara lain: hubungan partisipan (simetris/asimetris; intim-biasaformal-kaku-tidak ramah), skema aksi (argumentatif, diskursif, terangterangan, sembunyi-sembunyi, naratif, ritual, retoris, dan lainnya), dan orientasi terhadap lawan bicara (komunikatif, informatif, persuasif, manipulatif, dan lainnya)

\section{HASIL DAN PEMBAHASAN}

Elektra adalah tokoh utama yang memiliki kemampuan untuk berkomunikasi secara dialektis. Tapi, karena ia diciptakan dengan sifat plausible atau life-like, ia tidak statis. Elektra juga memiliki idealisme. Ini terlihat pada keputusannya untuk menitipkan Orestes, adiknya yang masih kecil, kepada Pak Tua sebab Orestes kecil masih belum mampu membantu Elektra untuk membalas dendam. Kata Pak Tua kepada Orestes dewasa, "Aku mengambilmu dari tangan kerabat dekat, yaitu dari saudara perempuanmu dulu. Aku membawamu pergi jauh, aku menyelamatkanmu, dan aku mengasuhmu hingga kamu sekarang bisa membalas kematian ayahmu." (Ewans, 2000: 3).

Idealisme Elektra bersifat aktif karena melibatkan tindakan nyata, bukan melulu menunggu Orestes kecil agar dewasa dulu dan mampu berperan untuk membalas dendam. Idealisme yang aktif dan produktif lebih tepat disebut sebagai dialektika. Elektra menerapkan prinsip: tidak ada kemungkinan yang statis atau konstan. Kata-kata "membawamu pergi jauh", "menyelamatkanmu", dan "mengasuhmu" kemungkinan besar adalah kata-kata Elektra sendiri yang diamanatkannya kepada Pak Tua. Elektra adalah pengirim pesan dan Pak Tua penerimanya. Dalam hal ini, Elektra memberikan pernyataan dan aksi sementara Pak Tua memberikan reaksi. Berdasarkan kata-kata yang digunakan, bisa disimpulkan bahwa percakapan antara Elektra dan Pak Tua waktu itu termasuk antagonistic dialogue karena tedapat kata-kata 
imperatif. Kemungkinan besar waktu itu Elektra mengucapkan "bawalah pergi jauh", selamatkanlah", dan “ asuhlah." Elektra menggunakan jenis kelas wacana yang berorientasi pada lawan bicara dan bersifat persuasif dengan skema aksi argumentatif dan sembunyi-sembunyi. Dia memengaruhi Pak Tua agar menuruti perintah-perintahnya dan dia berhasil.

Berbeda dengan Elektra, Chrysothemis memiliki idealisme yang statis. Percakapan antara dua perempuan bersaudara ini menampilkan demikian. Chrysothemis berkata, "Aku tahu apa yang terjadi di sini, sebenarnya aku sedih; seandainya aku punya kekauatan, akan kutunjukkan bagaimana perasaanku pada para pembunuh itu." (hal.12). Dalam menanggapi ini Elektra menyatakan, "Kamu bilang kamu benci mereka-tapi itu cuma kata-kata; tindakanmu menunjukkan kamu menaati para pembunuh ayahmu." (hal.13).

Idealisme Chrysothemis yang statis tampak dalam keadaan bahwa dia tahu tapi tidak melakukan tindakan yang tepat. Elektra, sementara itu, tahu apa yang terjadi dan tahu apa tindakan yang patut. Inilah dialektika Elektra. Dia tidak menunggu momen spesial untuk mengganggu para pembunuh ayahnya. Siang malam tanpa henti dia menangis meratapi kematian ayahnya dan ini merobek ketenangan para pembunuh yang saat ini sedang menguasai istana, tempat Elektra tinggal juga. Bagi Elektra yang dialektis, kata-kata saja tidak cukup; harus ada tindakan walau kecilsekecil tangisan dan ratapan. Tidak ada derau dalam percakapan ini. Chrysothemis hanya menyebut "perasaanku" tapi Elektra langsung paham dalam tindakannya dia mengatakan bahwa yang dimaksud adalah perasaan "benci". Ada oposisi atau kontradiksi. Oleh karena itu, percakapan ini masuk kategori antagonistic dialogue. Skema aksinya adalah argumentatif dan terangterangan. Orientasi Elektra terhadap lawan bicaranya adalah komunikatif dan informatif. Elektra mampu memahami maksud lawan bicaranya secara tepat dan mampu memberitahukan apa yang perlu disampikannya kepada Chrysothemis. Percakapan antara Chrysothemis dan Elektra yang akan dibahas berikut ini lebih jelas dalam mengungkap idealisme karena mengandung pengakuan dari si pembicara sendiri. Chrysothemis berkata, "Aku tahu apa yang kukatakan salah; apa yang kamu putuskan itu benar. Tapi kalau aku ingin hidup bebas, aku harus menaati para penguasa." (hal.12). Elektra menanggapinya dengan menegaskan, "Kamu punya kesempatan disebut putri dari ayah terhebat-tapi kamu memilih jadi anak ibumu. Semua orang akan tahu kamu salah, penghianat ayahmu dan kerabatmu yang masih hidup." (hal.13).

Chrysothemis akhirnya mengakui idealismenya salah dan dialektika Elektra benar. Kebebasan yang dirasakan Chrysothemis bersifat nisbi. Dia sebenarnya terkungkung dalam kegamangan di dalam dirinya. Sementara Elektra yang dari luar terlihat menderita karena terus disiksa penguasa, dia merasakan kebebasan sejati dalam dirinya. Elektra terbebas dari rasa bersalah dan ketidakberdayaan. Dia tetap berdaya dalam ketidakberdayaan, meskipun dalam batas terminimal. Sebagai penerima pesan, Elektra menanggapi ujaran Chrysothemis secara tepat. Tidak ada derau dalam percakapan ini walau tetap ada pertentangan. Ini termasuk 
antagonistic dialogue. Sama dengan sebelumnya, skema aksi yang tampak adalah argumentatif dan terangterangan. Hubungan partisipan dalam percakapan adalah tidak ramah dan orientasi Elektra terhadap lawan bicaranya ialah komunikatif dan informatif. Elektra sangat percaya diri dengan dialektikanya yang tak terpatahkan oleh idealisme Chrysothemis.

pernah disampaikan oleh Klytaimestra kepada Elektra. Klytaimestra berujar, "Dewi Keadilan membunuh dia, bukan cuma aku; kamu seharusnya membela Dewi Keadilan jika kamu gunakan akal sehatmu." (hal.17). Elektra menimpali ini dengan menegaskan, "Aku hendak bilang Anda tidak membunuhnya bersama Dewi Keadilan; lelaki hina yang tinggal bersama Anda sekarang itulah yang menekan dan membujuk Anda untuk membunuh ayah." (hal.18).

Klytaimestra berusaha memengaruhi Elektra dengan retorika religius. Dalam ratapannya, Elektra kerap menyebut nama-nama dewa dan dewi. Oleh karena itu, Klytaimestra menyusupkan Dewi Keadilan dalam argmentasinya dan pemfungsian akal sehat. Elekta tidak terpengaruh. Dialektika Elektra bersifat materialistis, ada wujudnya secara obyektif dan bisa dilihat semua orang. Elektra menyebut Aigisthos, selingkuhan Klytaimestra, secara implisit. Klytaimestra, sementara itu, menyebut Dewi Keadilan yang merupakan entitas abstrak dan tidak mungkin memihak kepada yang salah. Metafora Dewi Keadilan menunjukkan skema aksi yang ritual dan retoris. Inilah kelebihan komunikasi atau percakapan dalam karya seni fiksi. Hubungan antar partisipan adalah tidak ramah dan orientasi terhadap lawan bicara tampak komunikatif, informatif, dan manipulatif. Metafora Dewi Keadilan dimanipulasi oleh Klytaimestra tapi tidak berhasil ketika berhadapan dengan Elektra yang dialektis. Tidak ada derau yang menghalangi Elektra dalam memahami apa yang disampaikan Klytaimestra, ibu Elektra yang membunuh Agamemnon, ayah Elektra.

Tanda awal Elektra akan memperoleh keadilan yang didambakannya adalah sewaktu Klytaimestra memohon kepada Orestes agar tidak dibunuh. Dia berkata, "Anakku, anakku; kasihanilah ibumu." (hal.41). Kata-kata tersebut terdengar oleh Elektra yang memang menunggu-nunggu momen seperti ini. Karena tidak ingin banyak menyianyiakan kesempatan berharga, Elektra langsung menanggapi ini dengan, "Anda tidak mengasihani dia, atau ayahnya!" (hal.41).

Kemampuan berkomunikasi dialektis Elektra bisa dilihat pada kata-kata yang digunakannya agar jangan sampai Orestes terpengaruh oleh kata-kata ibunya. Elektra menegaskan bahwa buat apa mengasihani Klytaimestra kalau Klytaimestra sendiri tidak mengasihani Orestes sendiri dan ayah Orestes, Agamemnon. Ketika Orestes masih kecil, dia hendak dibunuh oleh ibunya tapi gagal karena Orestes kecil diselamatkan Elektra. Elektra mengungkit kesalahan-kesalahan Klytaimestra di masa lalu agar perbuatan-perbuatan buruk tersebut ternegasikan terutama dengan terbunuhnya Klytaimestra oleh Orestes atas dukungan Elektra. Percakapan yang melibatkan 3 tokoh ini bersifat antagonistic karena mengandung kata-kata imperatif ("kasihanilah"), vokatif ("Anakku, anakku"), dan adversatif ("tidak 
mengasihani"). Hubungan antara protagonis dan antagonis dalam percakapan ini adalah tidak ramah. Skema aksinya terang-terangan dan orientasi Elektra terhadap lawan bicaranya bersifat agresif.

Tanda kedua Elektra akan mendapatkan keadilan adalah tatkala Aigisthos mengakui bahwa perjalanan hidupnya berakhir. Dia berkata kepada Orestes, "Aku tamat. Tapi izinkan aku mengucapkan kata-kata terakhir." (hal.44). Elektra langsung menyergah dan berkata kepada Orestes, "Tidak! Demi dewa-dewi, saudaraku, jangan izinkan dia bicara lagi, dan mengulur waktu dengan kata-kata." (hal.44).

Kata-kata revolusioner Elektra "jangan izinkan dia bicara lagi" menunjukkan bahwa Aigisthos tidak perlu diberikan salah satu hak dasarnya, hak untuk bicara. Aigisthos terbukti pandai membujuk atau merayu orang dengan kata-kata. Selain itu, dia memiliki tendensi untuk mengulur waktu dengan kata- kata agar pengawal di istana datang untuk menyelamatkan dia. Hal-hal yang menguntungkan Aigisthos ini tidak perlu diberikan kepadanya dengan mengorbankan peluang Elektra dan Orestes untuk menghabisi Aigisthos. Dengan bersumpah menyebut dewadewi, Elektra yakin bahwa pembunuhan ini pasti direstui sang Maha Pencipta. Percakapan yang juga melibatkan 3 tokoh ini bersifat antagonistic dan hubungan antara protagonis dan antagonis kaku atau tidak ramah. Skema aksi protagonis terang-terangan dengan orientasi terhadap antagonis/lawan bicara bersifat agresif sesuai dengan sifat kejahatan terdahulu.

\section{KESIMPULAN}

Komunikasi transaksional dialektis mampu mengantarkan tokoh Elektra dalam meraih apa yang menjadi tujuan hidupnya. Unsurunsur komunikasi transaksional, yaitu timbal balik, pernyataan, tanggapan, aksi dan reaksi serta prinsip-prinsip dialektika: tidak ada kemungkinan yang statis atau konstan, memanfaatkan celah sekecil apapun demi tujuan mulia, membangun relasi kontradiktif demi penegasian kesalahan, dan berpihak pada revolusi bukan pada ketentraman khalayak tapi mengorbankan diri sendiri digunakan secara apik oleh Elektra. Tanpa komunikasi dialektis, patut diragukan Elektra bakal berhasil mendapatkan keadilan yang sebenarnya.

Selain untuk memperoleh keadilan, komunikasi transaksional dialektis dapat digunakan untuk tujuan-tujuan yang mulia yang ada dalam kehidupan manusia. Misalnya, dalam film Ada Apa dengan Cinta? 1 dan 2 apa yang menjadi tujuan tokoh utama adalah meraih cinta yang realistis bukan idealistis. Ini tidak serta merta mengandung pengertian bahwa tak perlu sama sekali adanya idealisme. Prinsip tersebut tetap perlu ada tapi tidak seyogyanya menjadi yang utama sehingga menghambat realisasi target yang semestinya bisa tercapai demi terpenuhinya kebutuhan.

Akan menarik manakala prinsipprinsip komunikasi dialektis digunakan untuk menganalisis fiksi mengenai keadilan dalam bidang pendidikan di tanah nusantara. Cerpen Danarto, misalnya, yang berjudul "Mereka Toh Tidak Mungkin Menjaring Malaikat" dirasa sangat layak untuk bahan kajian. Selain itu, cerpen Martin Aleida "Di Kaki Hariara 20 Tahun Kemudian" dan cerpen Triyanto Triwikromo "Serigala di

ISSN 2338 - 0861 (cetak); e-ISSN 2621 - 8712 (online)

website : http://spektrum.stikosa-aws.ac.id 
Kelas Almira" bisa dibaca dan dianalisis dengan teori komunikasi dialektis dengan fokus pada persoalan edukasi. Dua cerpen terakhir sempat masuk buku cerpen pilihan Kompas dan cerpen Aleida bergenre realistis. Sementara itu, cerpen Danarto dan Triyanto realistis-magis.

\section{DAFTAR PUSTAKA}

Aziz, Abdul Muhaiminul. 2005. A Character Study to Reveal Sophokles' Theme in Elektra. Unesa: Skripsi tidak diterbitkan.

Baxter, Leslie A."A Tale of Two Voices: Relational Dialectics Theory" in The Journal of Family Communication 2004, 4, 3\&4 .

Burgoon, Michael \& Michael Ruffner. 1978. Human Communication: A Revision of Approaching Speech. New York: Holt, Rinehart \& Winston.

Croucher, Stephen M. 2015. Understanding Communication Theory: A Beginner's Guide. Oxford: Routledge.

Ewans, Michael (ed.). 2000. Sophocles: Three Dramas of Old Age. London: J.M. Dent (Everyman). Data diterjemahkan ke bahasa Indonesia oleh Abdul Muhaiminul Aziz.

Hess-Luttich, Ernest W.B. "Dramatic Discourse" in Teun A. van Dijk (ed.). 1985. Discourse and Literature. Amsterdam: John Benjamins.

Lasswell, Harold. "The Structure and Function of Communication Theory" in Lyman Bryson (ed). 1948. The Communication of Ideas. New York: The Institute for Religious and Social Studies.
Palys, T. "Purposive Sampling" in L.M. Given (ed.) 2008. The Sage Encyclopedia of Qualitative Research Methods. Los Angeles: Sage.

Sasongko, Kresna Herka. "Ada Apa Dengan Cinta? Cinta Itu Harus Dialektis!" (2016) http: rumahkiri.org/ada-apa-dengancinta-cinta-itu-harus-dialektis/ diambil pada 7 September 2018 at 10:38. 